\title{
REGIONAL SITE RESEARCH
}

\section{By G. A. HILLS ${ }^{2}$}

\section{ABSTRACT}

Soil features, such as soil texture, mineral composition and soil moisture, and other features of land, such as topography, vary in their effect on forest growth depending upon regional climate. In Ontario, studies of land-forest relationships are conducted within the framework of site regions. Site regions are regions within which the effectivity of macroclimate is assumed to be relatively uniform since these regions are established through comparing the natural succession of vegetation on similar landforms, rather than by meteorological data. From the standpoint of forestry practice, the most pertinent feature of a site region is that it is an area in which similar responses may be expected from similar natural disturbances and forestry practices within similar combinations of landforms and forest types.

Regional site research embraces, within each site region:

(a) The establishment of landtypes and the description of the physiographic site types occurring within each landtype.

(b) The description of the forest types coinciding with stages of succession within each physiographic site type.

(c) The establishment of soil types coinciding with physiographic site types and major vegetation controls; also the establishment of variations in soil types resulting from differences in forest succession and forestry practice.

(d) The evaluation of each physiographic site type for producing forest and other crops.

Thus the aim of regional site research is (i) to describe the various physiographic conditions occurring in a site region so that foresters and land-use planners may recognize them, and (ii) to provide information regarding forest distribution, forest succession and the capability of these physiographic site types to produce forest and other crops, which information may aid these people in designing silvicultural experiments, in making forest management decisions, or in planning alternative uses of the land.

Examples have been drawn from the site regions of Ontario to illustrate the principles and methodology of regional research.

The Factors Which Influence Forest Growth and the Nature of Their INTERRELATIONSHIPS

The factors which influence forest growth may be considered under six broad groups, namely, soil, climate, vegetation, saprobes, fauna and man (Hills, 1958). Each of these groups is briefly described below.

Broadly speaking, soil refers to the complex of features which constitute the rooting zone of forest trees. Tree growth is dependent upon the quantity of the nutrient and toxic elements present, and of those elements, neither nutritive nor toxic, which control the degree to which the former are available to the plant. Other controls of tree growth in the rooting zone are

\footnotetext{
'Cost of publication shared by Research Branch, Ontario Forest Service, and the C.I.F.

${ }^{2}$ Mr. Hills is a member of the Research Branch, Ontario Forest Service, Maple, Ont. A biographical note was in For. Chron. 29(1): 128.
} 
available soil moisture, soil aeration, soil reaction, composition of the soil air, and soil structure. Many of these controls are related directly to the soil profile (which is soil in the classical sense), but others are more directly related to broader land features, such as topography, geologic materials and ground water.

Climate refers to a group of atmospheric features which supply the above ground portion of the forest vegetation with light, heat, water and carbon dioxide. Climate also provides for the movement and mixing of air, thus facilitating the supply of oxygen as well as carbon dioxide and heat to organisms both above the ground and in the soil.

The forest includes all the higher plants which synthesize material from sunlight and consists of both arboreal and lesser vegetation.

The fauna of the forest includes all the animals which consume either directly or indirectly, the products synthesized by plants.

Saprobes is a term which Whittaker (1957) introduced to designate the decomposers, the group of non-green organisms which reduce organic matter. This group consists chiefly of micro-organisms but includes larger organisms such as the fungi. They function as the reducers of the products of photosynthesis as well as of inorganic elements. Saprobes, such a mycorrhizal fungi, are normal features of the forest productivity system. Others, however, such as the pathogens, are erratic in their occurrence and exert their greatest control when their numbers reach epidemic proportions.

Four of the six groups of features, namely, soil, climate, forest and saprobes, are essential in the natural development of forest succession. Fauna and man, as well as certain elements of the four groups already mentioned, disturb the natural successions, either favourably or unfavourably. Man's disturbance of the forest may be either (1) occasional and or irregular, such as forest fires set by travellers in the forest, and forest highgrading, or (2) sustained or regular, such as planned logging operations, silvicultural treatments, land clearing and tree planting.

If man is excluded, there are five groups of natural features within a forest productivity system. The total number of individual features into which these five groups of significant features may be divided is by no means small. To add to the complexity, not one of these individual features exerts a constant effect on forest growth, but each feature varies according to variations in the others. This is the result of the reciprocal effects which these features exert upon one another. The following examples illustrate the complexity of these interrelationships.

In the humid regions, coarse sandy soils provide trees with less moisture than do the fine-textured clays and silts. In the dry regions of the same temperature belt the reverse is true. For example, cross-timber areas of Texas are forested sand ridges within grass-covered clay plains. Evidentally the clay holds to itself the small amount of water which falls, while forests once established, can secure sufficient moisture from the sand before it disappears into the air or underground.

In the zone between forests and grass a greater number of inches of rainfall is needed for forest growth in the hotter, than in the colder regions. Another interrelationship between climatic features is the greater effectivity of tempera- 
ture with the decrease of humidity in boreal regions. Two regions with the same absolute temperature may have different effective temperatures. In the less humid region of the two, less heat is used to evaporate excess moisture leaving more heat available for the activity of both soil organisms and plants.

These examples should be sufficient to demonstrate that definite relationships cannot be established between forest growth and absolute levels of individual features, whether these features be soil, climate, forest, saprobe, fauna or man. Other examples will be presented later with reference to the site regions of Ontario.

\section{Site-The Place of Forest Production}

In the preceding discussion, it was demonstrated that forest production was controlled by local complexes of all the features affecting forest growth. Since many, if not all, the features in any area vary within short distances, a relatively homogeneous system for producing forests is confined to a relatively small area of the earth's surface. This relatively homogeneous area or place of forest production is called site (Hills, 1952, Hills and Pierpoint 1960).

Site, in common with other places, is described in terms of its living, as well as its non-living, characteristics. It is true that the physical features of the land surface (soil in its broadest aspect) are very useful in locating the boundaries of site units. However, unless the succession of vegetation, which is associated with these land features, is known, the sites cannot be adequately described and differentiated from one another. For, as mentioned above, forest production varies on the same soil with variations in climate.

The above statement holds true only if we consider soil in its broader meaning as the rooting zone of plants and described in terms of landform, i.e. relief and type of geologic materials. If we conceive soil in the classical taxonomic sense of a profile of various horizons resulting from soil weathering, the statement may, or may not, hold true. Soil profiles do vary with changes in climate and concomitant changes in vegetation. But soil profiles also vary through differences in landform and in vegetation succession within the same climatic region. This suggests that a useful physical base must consider both landform and climate in such a way that both the broader and narrower concepts of soil will be included. In this paper, this physical base is called physiographic site since it is but one portion of the total site complex. A pattern of physiographic sites is known as land.

Site has been defined by the American Society of Foresters as "an area, considered as to its ecological factors with reference to capacity to produce forests or other vegetation; the combination of biotic, climatic, and soil conditions of an area" (Soc. Am. For., 1950). In brief, site is a forest productivity system and as such is a combination of both land and forest. Operating within and between the forest and the land are processes which transform and transfer the energy and matter utilized in forest production (Ovington, 1960).

Site, the local productivity system, is comprised of five subordinate systems, namely, soil, climate, plants, saprobes and animals (Hills, 1958). Intermeshed with the multitudinous local productivity systems are four superior systems which supply energy to the local systems and, in many other ways, control forest production within them. Reference has already been made to the 
physical base called land which is a combination of two superior systems, namely, the continental continua of landform and of macroclimate. The latter, macroclimate, is that portion of the atmosphere which is relatively unaffected by local landform irregularities and is thus distinguished from the local climate of site known as ecoclimate. Man's cultural system is also one of the superior controlling systems. Another is the continental biosystem of plants and animals which supplies genetic strains of organisms which successively colonize the site. Figure 1 shows the relationship between the superior systems and the subordinate systems which comprise the ecosystem.

A Base for Comparing the Effect of Factors on Forest Production

In the above discussion it has been pointed out that there is no constant relationship between forest growth features and a specific level or quantity of a specific element of the environment. It is possible to have, in fact, a considerable variation of a specific important factor controlling forest growth within two sites, but yet have no difference in forest growth because of variations in other factors which compensate for the variations of this specific factor.

Since the significance of the variation in any one feature is dependent upon the total effect of all the features in the complex, it is logical to approach the evaluation of site factors through a classification of the site complex as a whole.

At first thought, viewing the problem entirely in the light of statements made above, it might appear impossible to establish a logical scheme of classification. There are so many factors at so many levels of intensity and with no widespread constancy of significance of these levels with forest growth. However, as one travels from the torrid or even the temperate south to the boreal north, or from the humid east to the dry continental interior, there appear changes in the forest-land relationships which suggest some orderliness of control of plant distribution.

Changes are generally most marked if comparisons are made of places separated by long distances. If changes in climate were uniformly effective at the earth's surface, the resultant changes in site would occupy positions within a continuum and sites would be ordinated geomathematically on the earth's surface.

However, in making a continental traverse in the direction of change in effective temperature, the elements of three forests will be observed whenever an area of any size is considered. There is the forest element which is dominant throughout this large area. There is also the element which has dominated a broad belt in the colder areas left behind, likewise the element which will be found to be dominant in the warmer belt ahead.

Thus it is necessary to consider not one but three continua of forests (associations) within any given area. These associations are not of continental extent for one fades out, and is replaced by another.

In examining the distribution of these three forest elements in any local area, it is found that these occur in the climax stage on three distinct landform classes. The landforms which express the normal effect of regional climate are undulating areas of well-drained loamy soils. Landforms such as depressions with poor air drainage have local climates which are effectively 
DECEMBER, 1960

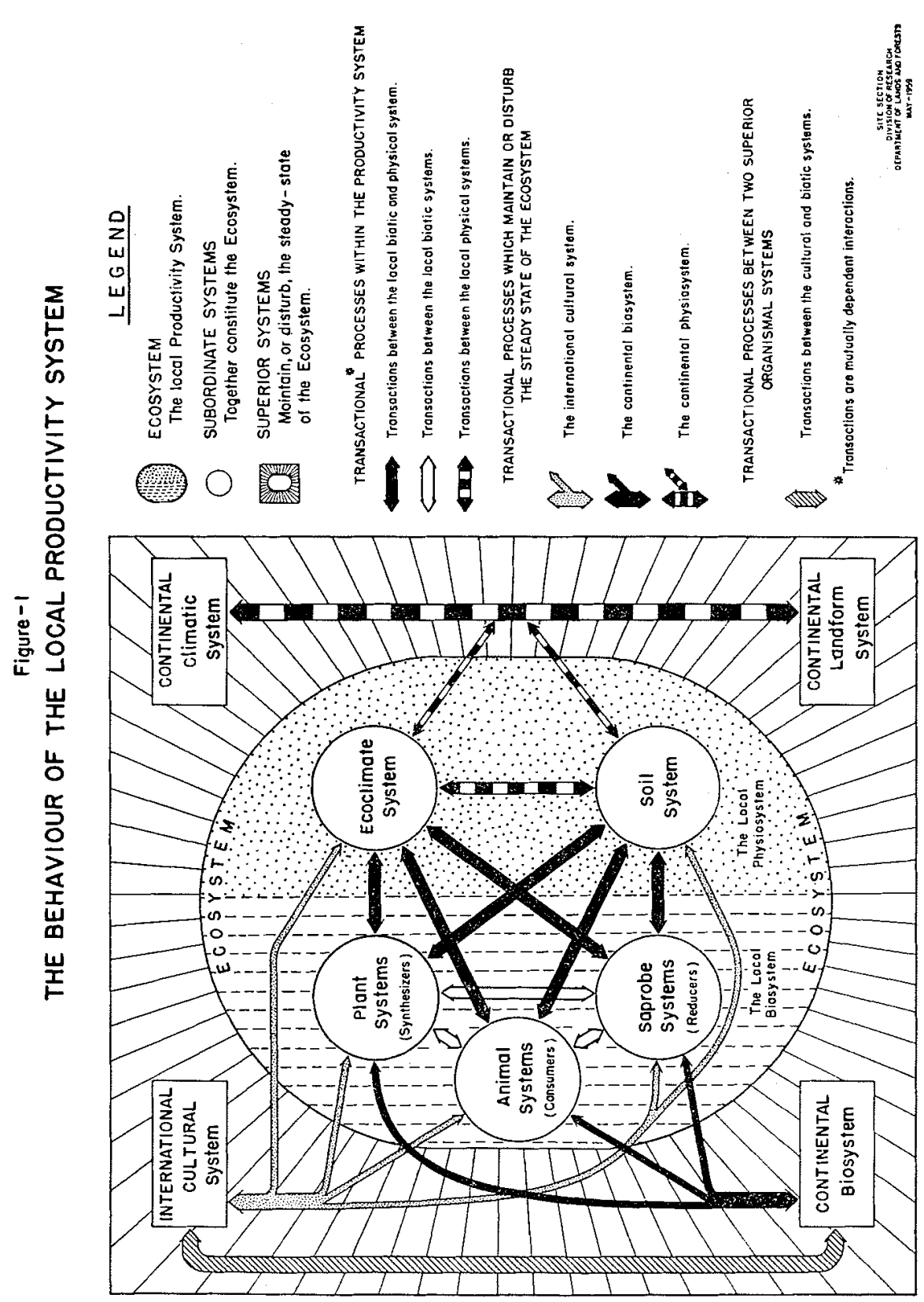


colder than normal and support the elements of a forest from a colder region. Landforms such as protected valleys and upland coves have warmer than normal local climates and support the elements of a forest which dominates a more southerly region.

The distribution pattern of forest associations recognizable in a traverse from Hudson Bay to the Gulf of Mexico is shown in Figure 2. If the traverse passes from Moosonee, Ontario, to Mobile, Alabama, along a direct route, the following forest associations may be recognized: $F_{0}-$ Open Spruce-Lichen, $F_{1}$-Boreal Spruce-Fir, $F_{2}-$ Hard Maple-Yellow Birch, $F_{8}-$ Hard Maple-Beech, F-Tulip-Sycamore, and $F_{\sigma}$-Oak-Southern Pine.

Figure 3 illustrates the change in forest elements with each macroclimatic change in temperature. As the temperature changes, the forest elements change their position with reference to the landform classes. In going southward the forest association $F_{0}$, which at $T_{0}$ occupied the gently undulating loamy slopes (the normal landform, $L_{n}$ ), gradually shifts at $T_{1}$ to valleys and depressions with poor air drainage (landform effectively colder than normal, $\left.\mathbf{L}_{c}\right)$. The elements of the forest association which at $T_{0}$ occupied the protected coves and valleys with good air drainage (landform effectively warmer than normal, $\mathbf{L}_{w}$ ) now take over on the normal landform $\left(\mathbf{L}_{\mathfrak{n}}\right)$, and the elements of the forest association $F_{2}$ which dominate a region farther south at $T_{2}$ now appear on landforms of class $\mathrm{L}_{\mathrm{w}}$.

\begin{tabular}{|c|c|c|c|c|c|c|}
\hline $\begin{array}{c}\text { Dominance } \\
\text { of } \\
\text { Forest Element }\end{array}$ & & & & & & \\
\hline Decreasing & & $F_{0}$ & $F_{1}$ & $F_{2}$ & $F_{8}$ & $F_{4}$ \\
\hline Maintained & $F_{0}$ & $F_{1}$ & $\mathbf{F}_{2}$ & $F_{a}$ & $\mathbf{F}_{\mathbf{a}}$ & $F_{s}$ \\
\hline \multirow[t]{2}{*}{ Increasing } & $F_{1}$ & $F_{2}$ & $\mathbf{F}_{8}$ & $F_{4}$ & $\mathbf{F}_{5}$ & \\
\hline & (Cold) $\mathrm{T}_{0}$ & $T_{1}$ & $T_{2}$ & $\mathrm{~T}_{s}$ & $\mathrm{~T}_{4}$ & $T_{5}$ (Hot) \\
\hline
\end{tabular}

FIGURE 2. The vegetation spectrum reflecting the control of landform and macroclimate on forest distribution.

In travelling from the humid regions of eastern Canada to the arid regions of the western plains, a similar change in the pattern of forest-landform relationships is noted. A figure similar to figure 3 can be drawn to show differences in vegetation succession on (i) normal landform, (ii) landform effectively wetter than normal, (iii) landform effectively drier than normal. For example, as one approaches the prairie regions, southern upper slopes may be prairie or parkland, and the northern and lower slopes of the same hill may support closed forests. In order to keep this discussion as brief as 


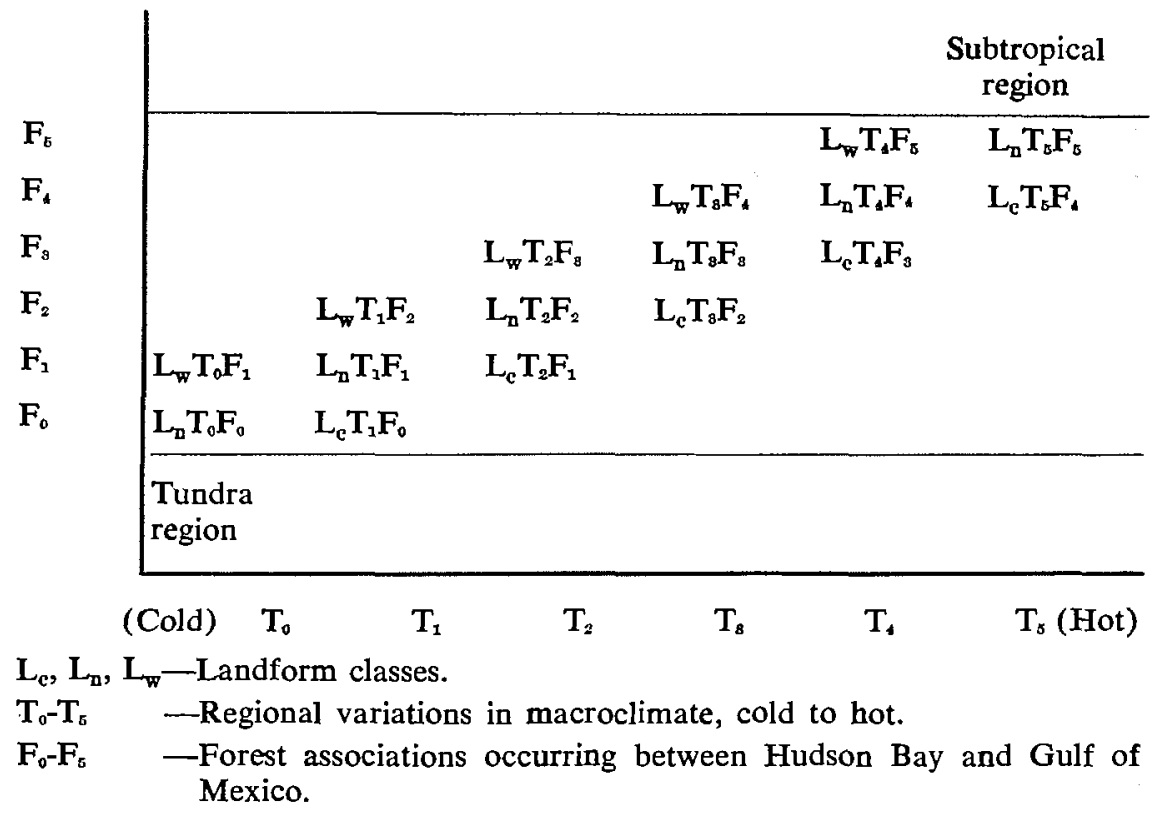

FIGURE 3. The relationship between forest associations, landform and regional differences in macroclimate.

possible, only segments of the atmospheric humidity continua will be discussed in the following example.

Suppose we examine, from some well-chosen vantage point, an area which stretches several hundred miles in all directions. Let us take, for example, a station which represents the $L_{n} T_{2} F_{2}$ in Figure 3. This station will be one of a number of well-drained sites $\left(\mathrm{L}_{\mathrm{n}}\right)$ in climatic region $\mathrm{T}_{\mathrm{z}}$ which support a climax forest of hard maple and yellow birch $\mathbf{F}_{2}$.

First, let us examine the local differences in forest growth and forest succession due to differences in land form and in disturbances by natural or cultural causes. On the undisturbed forests on the colder wet depressions and northern slopes we find elements of the boreal spruce-fir forests of region $T_{1}$. Also on the dry ridge tops and upper south slopes are elements of hard maple, beech, oak. Forests of region $T_{2}$, under severely disturbed conditions, would be composed of pioneer species, such as the aspens and jack pine.

As we look away from this central station, we would note that these patterns are repeated, time and time again, over relatively great distances. This pattern would not be ordinated geomathematically, but would be determined by the natural distribution of landform and other landscape features, and by the activities (both orderly and by chance) of man and nature. However, at points occurring at considerable distances from the initial observation point, the forest succession on a specific landform in these outer areas is no longer the same as that initially noted on the same landforms in the focal 


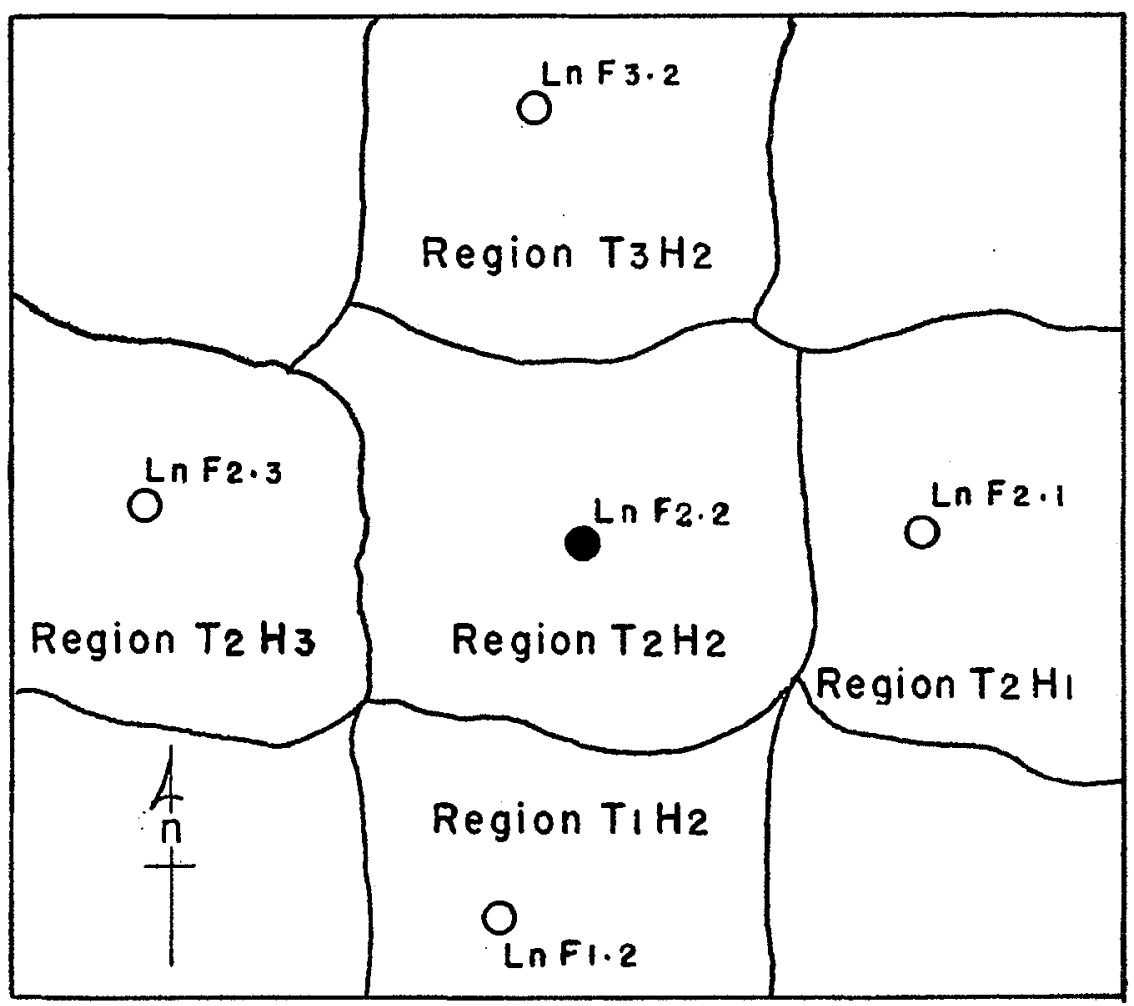

- Focal area of region $\mathrm{T}_{2} \mathrm{H}_{2}$ and central observation station.

O Focal point of bordering regions.

Ln.Normal landform. The characteristic climax forest ( $F_{2.2}$ etc.) on this landform is indicative of regional differences.

Figure 4 . The establishment of five forest association regions. 
area. Nor are the landform-forest relationships the same in all the places in this outer circle. The difference in forest-landform relationships indicates a difference in the temperature and humidity of the macroclimate.

That there are differences in landform-forest relationships at these distant points does not necessarily mean that the landscape is entirely different. Many, perhaps all, of the landforms will be the same. Not a few of the forest types will be the same. In a few instances, the same pioneer forest type will be found on the same landform. It is the change in the pattern of relationship between landform and forest succession which is significant.

Although differences in landform-forest relationships are noted between stations found at various points along this outer circle, local differences are not marked. Therefore, before a boundary can be established for the region which is characterized by a consistent pattern of vegetation-landform relationships, noted at the initial observation point $\left(\mathrm{L}_{\mathbf{n}} \mathrm{T}_{2} \mathrm{~F}_{2}\right)$, it is necessary to establish other focal points at suitable places located in all directions from the initial focal point.

Two of these will show difference in macroclimatic temperature, namely, differences as already established at $T_{1}$ and $T_{a}$.

Another two of these border regions will show differences in macroclimatic humidity. For convenience, let us establish three humidity regions, namely, $\mathrm{H}_{2}, \mathrm{H}_{2}$ and $\mathrm{H}_{3}$, ranging from moist to dry, and let region $\mathrm{H}_{2}$ coincide with region $T_{2}$. Thus the climate of the focal region becomes $T_{2}, H_{2}$. Figure 4 shows the focal region and four bordering regions, defined in symbolic terms indicating normal landform plus macroclimate and the climax forest related to this combination. Since the adjacent regions to the east and to the west will have somewhat comparative temperature effectivity, the climate may be designated $\mathrm{T}_{2} \cdot \mathrm{H}_{1}$ and $\mathrm{T}_{2} \cdot \mathrm{H}_{3}$.

The forests of regions $T_{2} \cdot H_{1}, T_{2} \cdot H_{2}$ and $T_{2} \cdot H_{8}$ will differ largely in elements reflecting effective humidity. Differences in forests in these three regions will now be noted to determine the local conditions reflecting greater and lesser degrees of effective air humidity.

For example, in region $\mathrm{T}_{2} \cdot \mathrm{H}_{2}$, well-drained sites of the climax forests with moister-than-normal air humidity will frequently contain the red sprucehemlock stands which are characteristic of sites of normal air humidity in region $\mathrm{T}_{2} \cdot \mathrm{H}_{1}$. The sites which are drier (but not hotter) than normal will support climax forests of bur oak, a characteristic of the forests of sites of normal air humidity in region $\mathbf{T}_{2} \cdot \mathrm{H}_{8}$.

It is now necessary to establish four additional focal points from which the process of observing changes in landform-forest relationships will be repeated. These focal points should be established on a trial basis, shifting focal points, if necessary, in order to establish sufficiently narrow, but distinctive, differences in vegetation-landform relationships.

Boundaries of regions are not so easily established as are the core areas. Local changes in landform-forest relationships are seldom significantly abrupt unless there is a marked discontinuity in landform features, such as a rapid change from level plain to steep mountain slopes. Consequently, regional boundaries are located at points where the patterns on one side of the 
boundary are more similar to the focal (or core) area on that side than to the focal area on the other side of the line.

The regions so established (Fig. 4) are forest association regions. In establishing these forest association regions we have used actually five reference points: (1) normal, which is the gently undulating well-drained sites, (2) colder than normal, (3) hotter than normal, (4) moister than normal (air), (5) drier than normal (air).

Since these forest association regions cover a very wide range of soil and climatic conditions, a refinement of forest association regions into forest site regions has been accomplished (Hills, 1958). Each of the three to five local climate classes are subdivided into three on the basis of soil moisture (dry, normal and wet soil). The resulting landform classes (nine to fifteen) provide the physiographic basis for the separation of site regions. (See key to Map 1.)

\section{StTe Region}

A site region is an area in which the same vegetation succession will occur on the same physiographic site, providing the type and degree of disturbance is the same. The site region provides the forester with a framework in which he can apply management practices and the findings of silvicultural research with a reasonable degree of assurance of their success (Hills, 1958).

That similar responses may be expected from similar combinations of landform, forest types, natural disturbances and forestry practice stems from the fact that it is a region of relatively uniform effective climate. The establishment of regions within a narrow range of macroclimate has been accomplished by the use of the distribution patterns of natural vegetation, as described in the preceding section, and not through the use of meteorological data (Hills, 1959).

A site region is a peculiar type of forest region since it is established by noting the succession of forest types on the major landform classes. This peculiarity is explained more fully in the discussions of the site regions of Ontario.

A site region is a peculiar type of soil region since soil formation is controlled by combinations of climate, landform and vegetation.

A site region is a peculiar type of land-use region. Although differing in degree, the environmental controls of forest growth also function in controlling crops of the field, pasture and wildlife forage.

\section{STre District}

A site district is a fairly large subdivision of a site region, which is set apart from other areas because of a characteristic pattern of landform features. For example, the dominance of certain landform patterns, such as those of a lacustrine plain, will result in a pattern of landform-forest combinations differing from that of a drumlin field.

Since site districts are areas of convenience, they do not necessarily represent the full scale (or any unique part) of the gradients of sites which characterize the site regions as a whole. Site districts do have a commonly occurring pattern of sites which occupy definite parts of the regional scale.

If the landform is a relatively smooth homogeneous clay plain, the 
number of the landscape units will be relatively few and of a homogeneous nature, and the sites of such a district will occupy relatively narrow portions of the regional gradients.

If the landform has very broken relief and a wide range in soil materials, the landscape units will themselves be more variable than those of the clay plain, and the number of landscape types will commonly be greater in number. The sites of such a site district may occupy widely separated portions of the regional gradients.

For a description of the site districts of Ontario see "A Ready Reference to the Description of the Land of Ontario and its Productivity" (Hills, 1959).

\section{Regional SITE Research}

Regional site research does not end with the establishment of site regions, nor with the establishment of site districts within a site region. Indeed, regional site research is just nicely begun at this stage. The landforms of the site region must be studied in detail in order to establish groups of landform features which are ecologically equivalent within the region. It is true that the site region has already been established on landform-forest relationships, but only on a very broad basis with very broadly defined reference points.

Groups of landform features within a site region are called landtypes (i.e. types of land) being specific combinations of landform and climate (Hills, 1959, p. 2). Landtypes have a relatively uniform pattern of forest productivity since they are confined to a region of uniform effective climate. Since the same landform occurs in more than one site region, its production varies with climate. Landform, alone, is therefore not a satisfactory base upon which to rate forest production but is, however, a useful guide. A specific landform often occupies the same relative position in a scale of potential production within two or more contiguous regions. It is necessary, nevertheless, to evaluate the potential of the landforms in each region separately. To save confusion, it has been deemed advisable, in the initial stages of evaluation, to relate potential production to landtypes which are specific for the region (Hills and Brown, 1955; Pierpoint, 1960).

Landtype may be defined as land of a certain type within a site region, being defined in terms of classes of geologic materials and possessing a relatively consistent pattern of production potential.

If the materials are unconsolidated, broad classes of texture and mineralogical composition (Hills, 1954) are the basis for differentiation into types. For example, a class of coarse and medium sand, with or without gravel, is separated from a class of fine sands and silty sands with a relatively high percentage (not higher than $50 \%$ ) of silt. The remaining textural classes are placed in three groups, viz. loam, silt and clay.

Each class may be subdivided on the basis of mineralogical composition. For example, coarse and medium sands may be very low base, if derived from granitic rock and low base, if derived from dioritic rocks. Likewise, fine sands may also be very low base, if derived from granitic rocks or low base, if derived from dioritic or basaltic rocks.

Bedrock strata which influence the rooting zone of trees are classified on the basis of mineralogical composition (same classes as for unconsolidated 
material) and, in place of texture, the degree of resistance to weathering. Granite, for example, is usually classified as very low base and strongly resistant to weathering. Shale, on the other hand, an argillaceous bedrock, is weakly resistant to weathering.

Texture and mineralogical composition are but two of the landform features which could be used to define a landtype. However, they have been chosen as the ones which are most useful at the level of integration required for making broad comparisons between regions. The depth of any given material over bedrock (or other material having significant effect on forest production) is the basis for establishing a series of related landtypes.

Although the productivity patterns associated with these combinations of geologic material classes are distinctive for each site region, each landtype is itself a pattern of forest productivity within a region. Differences in such features as soil moisture regime, slope, aspect and many others are responsible for these differences within landtypes.

Accordingly, the landtype is subdivided into physiographic site types based upon: (i) Ecoclimatic (local climate) classes dependent upon relative mass elevation, slope and aspect. (ii) Moisture regime classes characterized by those soil profile features which reflect drainage.

Although landtypes and physiographic sites are defined in terms of broad classes of landform features which apply to all regions, detailed definition for each region is required in order that all the ecologic equivalents within a class may be readily recognized. In order to do this, a detailed knowledge of the landform-forest relationships throughout the region is necessary. This regional refinement of the definition of classes does not obscure the basic reference classes, but provides firm definitions for units within the region.

The discussion so far has dealt with the establishment of the physiographic portion of site. Mention has been made of effective levels of climatic and landform features upon forest production. Reference also has been made in the above paragraph to refining the definitions of physiographic classes through a detailed knowledge of landform-forest relationships within a region. Nevertheless, many workers have assumed that we, in Ontario, establish physiographic site types independent of the forest types (Krajina, 1960). This is not the case.

Since there must be a fitting of forest to physiographic sites, neither physiographic nor biotic types can be established a priori (Cf. Krajina 1960b). The classification of both groups of features must proceed concurrently. It is, of course, necessary to locate, in terms of landform features, the place where differences in the effect on forest production by climate, landform and other controls of forest succession and of soil development may be observed. Consequently, physiographic site features are usually discussed first in order to orient the other controls of forest production (Hills, 1959).

A forest type is the biotic (i.e. living) portion of a forest productivity system. A forest type is defined in terms of the species composition and other characteristics of the forest and lesser vegetation which reflect their relationship to both the physiographic environment and to the other controls of forest succession in relation to the physiographic environment (Hills, 1954).

The manner in which the physiographic environment has been organized 
to show the ecologic amplitude of forest communities has been discussed previously. The feature which has been used for this procedure, although not defined until now, is that kind of forest type which represents a relatively narrow, but distinct, stage of forest succession upon a relatively narrow range of physiographic conditions.

The same forest type is not necessarily confined to a single stage of succession on a single physiographic site type. It may represent different stages in succession on different physiographic site types.

Thus the key to the greater success of the proposed system of site classification compared to that of other systems of classification is the concurrent establishment of physiographic and forest types (Hills, 1959; Rowe et al., 1960). Forest types are often establshed $a$ priori on the assumption that similar forests must have similar environmental controls. Such an assumption does not take into account the compensation of factors. Neither is any a priorl classification of climate, soil or landform adequate since these are based on only one portion of the total productivity complex.

Having obtained a detailed knowledge of the factors controlling forest productivity throughout the region in order to establish the site units which combine physiographic and forest types, the site research worker is in a very good position to suggest the use of these units in evaluating the potential of forest land for the regeneration and growth of forest crops (Hills and Pierpoint, 1960).

\section{The Site Regions of Ontario}

Using the principles outlined above, twelve site regions are now recognized in Ontario (Hills, 1959). Originally, only seven regions were established (Hills 1952). These were based on differences in effective temperature which are the most marked climatic controls in Ontario. Later, however, significant differences in humidity were noted and a subdivision of four of the original regions resulted in eleven site regions (Hills, 1958). Further recent revisions, also based on effective humidity, are shown on Map 1.

This map shows the province divided into seven belts from north to south, and three belts from east to west (Hills, 1960b).

The belts, which form a tier from north to south, indicate variation in effective temperature. If the temperate zone of North America is divided into three sub-zones, most of Ontario would be in the most northerly of these, which is often called the microthermal zone. The most northerly region (Site Region $1 E$ ) is actually a transition from this microthermal climate to that of the tundra. The microthermal climate stretches from site region $1 \mathrm{E}$ southward to the southern edge of the Canadian Shield. Because of differences in the pattern of landform-forest relationships, this microthermal sub-zone has been divided into five regions. Site region $7 \mathrm{E}$ lies in the middle or mesothermal sub-zone of the temperate zone. Site region $6 \mathrm{E}$ is a transition between the microthermal and mesothermal sub-zones.

The belts which are arranged from east to west indicate variations in effective humidity. The broad zone of moist climate, which stretches from the Atlantic Ocean to the arid interior, may be divided into three sub-zones, namely, perhumid, humid and subhumid.

The humid sub-zone may again be divided into three, namely, the wettest 


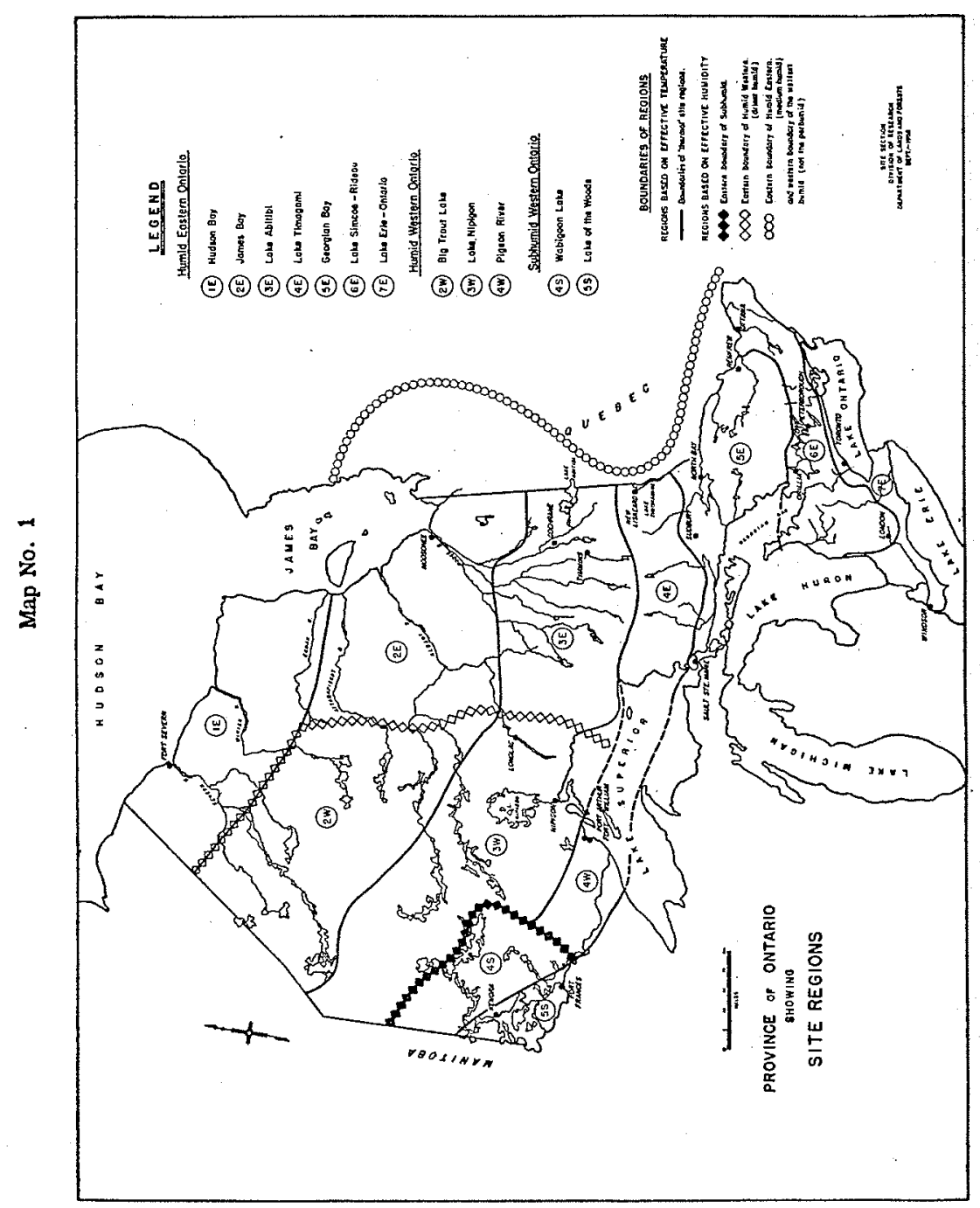




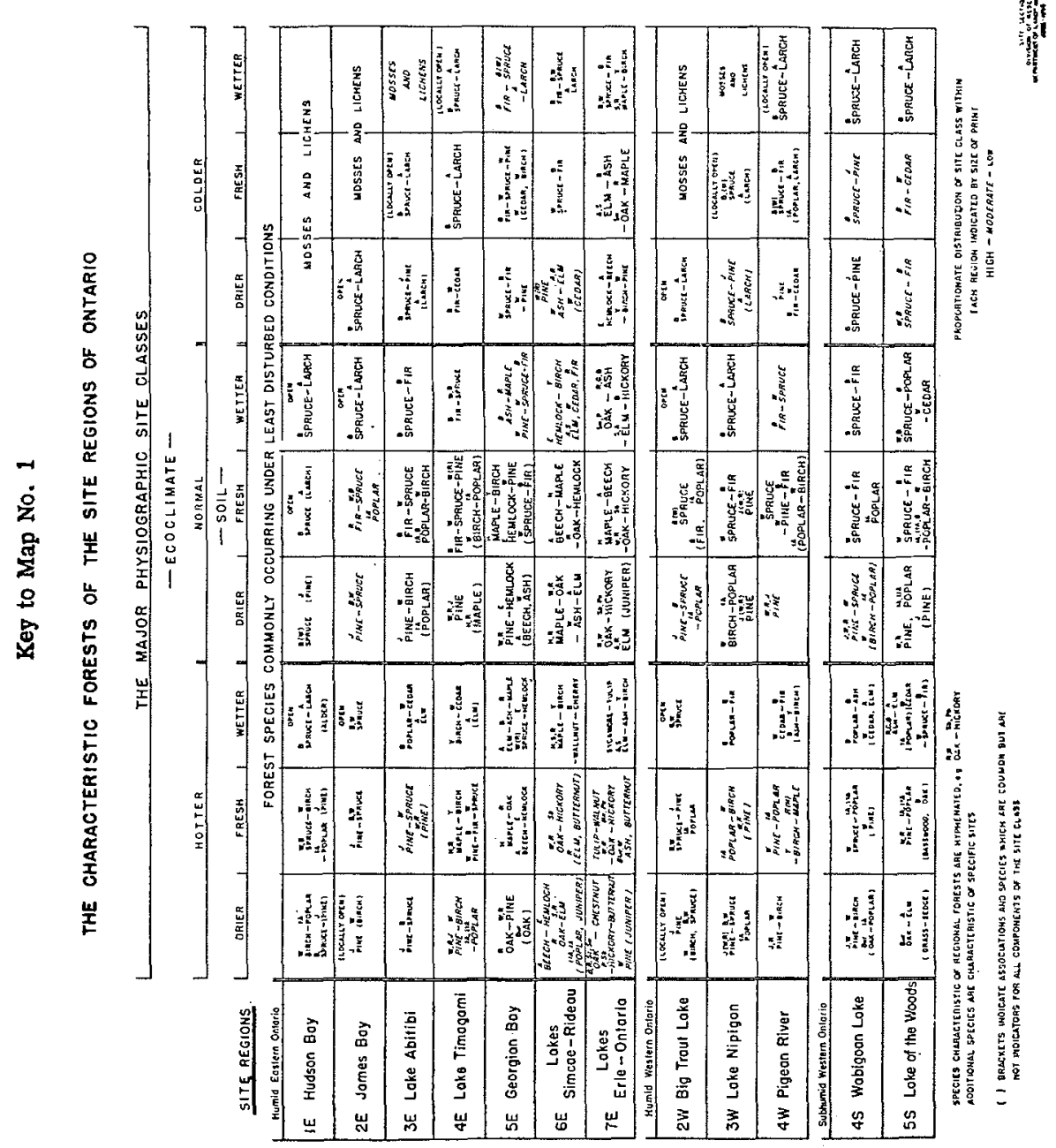



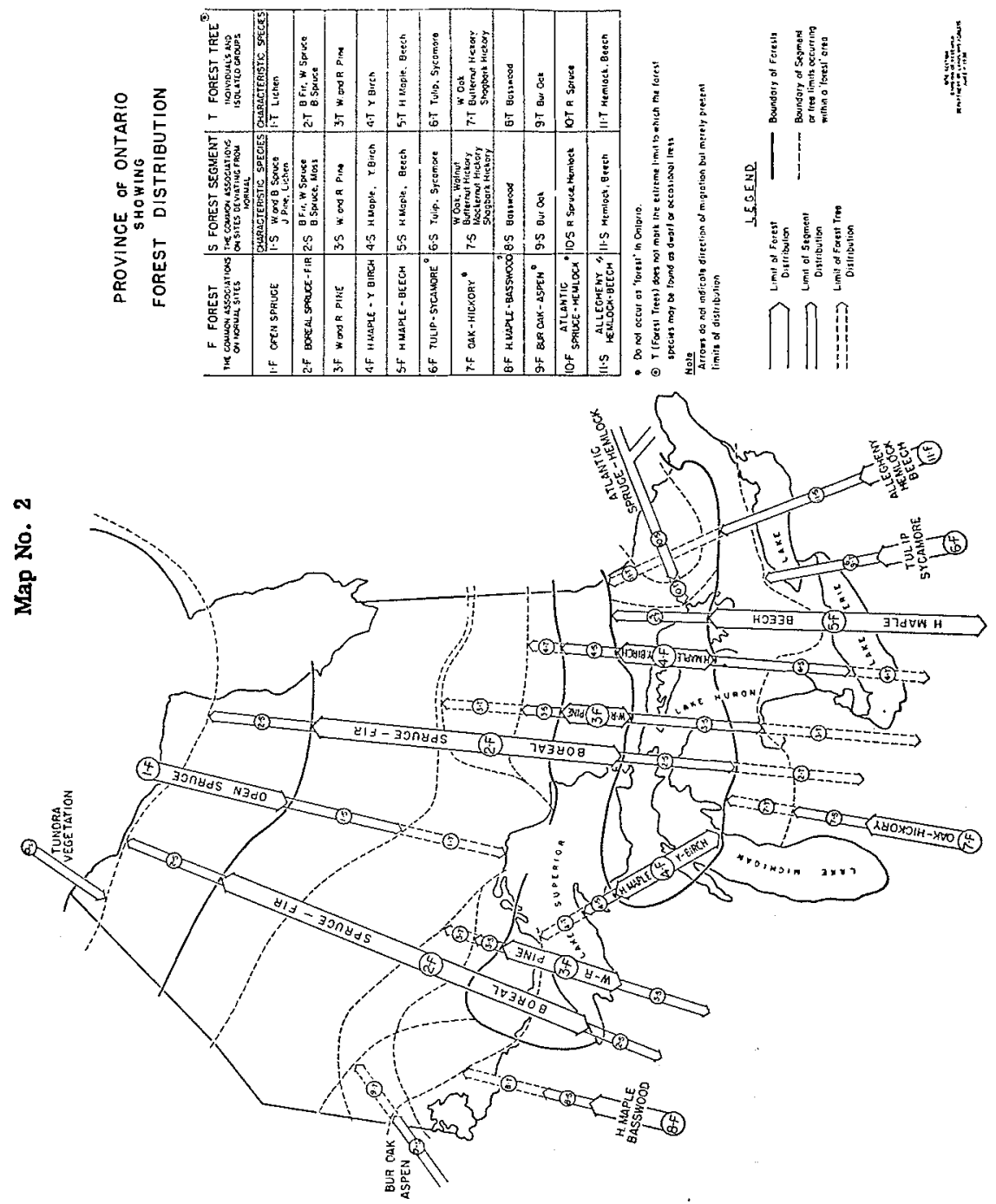
humid, the medium humid, and the driest humid. Ontario lies in the medium and driest humid, and the subhumid belt.

Within the medium humid regions (Nos. 1E to $7 \mathrm{E}$ ), there are locally wetter areas (perhumid or wet humid), chiefly to the east of Lakes Superior and Huron.

The above differences in regional climate were established not by meteorological instruments, but by noting differences in the succession of forest types on the specific landform classes. Accordingly, site regions are regions having a definite pattern of vegetation. However, regions are not characterized merely by the presence or absence of a species, but also by the physiographic niche in which it is found.

White spruce, for example, is found in all site regions in Ontario, but occupies different niches in each. (See Key to Map 1). It moves from the warmest sites in the north to the coldest and wettest in the south. It is found on all ranges of soils, from dry to wet, and on all ranges of local climate, from hot to cold, if all the regions of Ontario are considered, but it never occupies the full range of soil moisture or local climate in any one region.

Map 2 is a graphic summary of this type of forest distribution pattern (Hills, 1959). Again, take white spruce, for example. In regions $2 \mathrm{E}, 3 \mathrm{E}$ and $4 \mathrm{E}$, white spruce and balsam fir dominate the climax stands on the well-drained sites $^{3}$. This type of distribution is recognized as a regional forest. In region $5 \mathrm{E}$, white spruce and balsam fir form climax stands only on sites which are too poorly drained for hard maple and yellow birch, the forest species which are characteristic of this region. These white spruce-balsam fir stands are considered forest segments, even though their areal distribution may be fairly extensive. In regions $6 \mathrm{E}$ and $7 \mathrm{E}$, white spruce and balsam fir are rarely found in stands, but they occur as individuals in stands of mixed conifers and hardwoods.

The greater effective temperature of region $7 \mathrm{E}$ is reflected in the extension of segments of the oak-hickory and of tulip-sycamore forests from the south.

The greater effective humidity of region $5 \mathrm{E}$ is reflected in the extension of segments of the forests of red spruce and hemlock from the maritimes.

The subhumid aspects of region $5 S$ are reflected in the extension of the bur-oak and aspen parklands of the prairie provinces.

Map 3 shows the combined effect of climate and vegetation on soil development. In order to eliminate, as far as possible, variations due to differences in landform, certain of these features have been used as reference points (Hills, 1960a).

One of the most important requirements in the development of a productive agricultural soil is the relatively rapid breakdown of organic matter. This is usually indicated by a surface soil of good structure in which the humus is well incorporated with the mineral matter (Hills, 1960b).

Since these processes are dependent upon chemical and biological activity, they proceed most rapidly in a well-aerated soil, fairly well supplied with available moisture and nutrients.

Although good forests may be produced on raw humus sites, it has been found that, in the humid microthermal regions of Ontario, the local physio-

3 This statement also applieg to regions $3 \mathrm{~W}, 4 \mathrm{~W}$, and $4 \mathrm{~S}$. 
Map No. 3

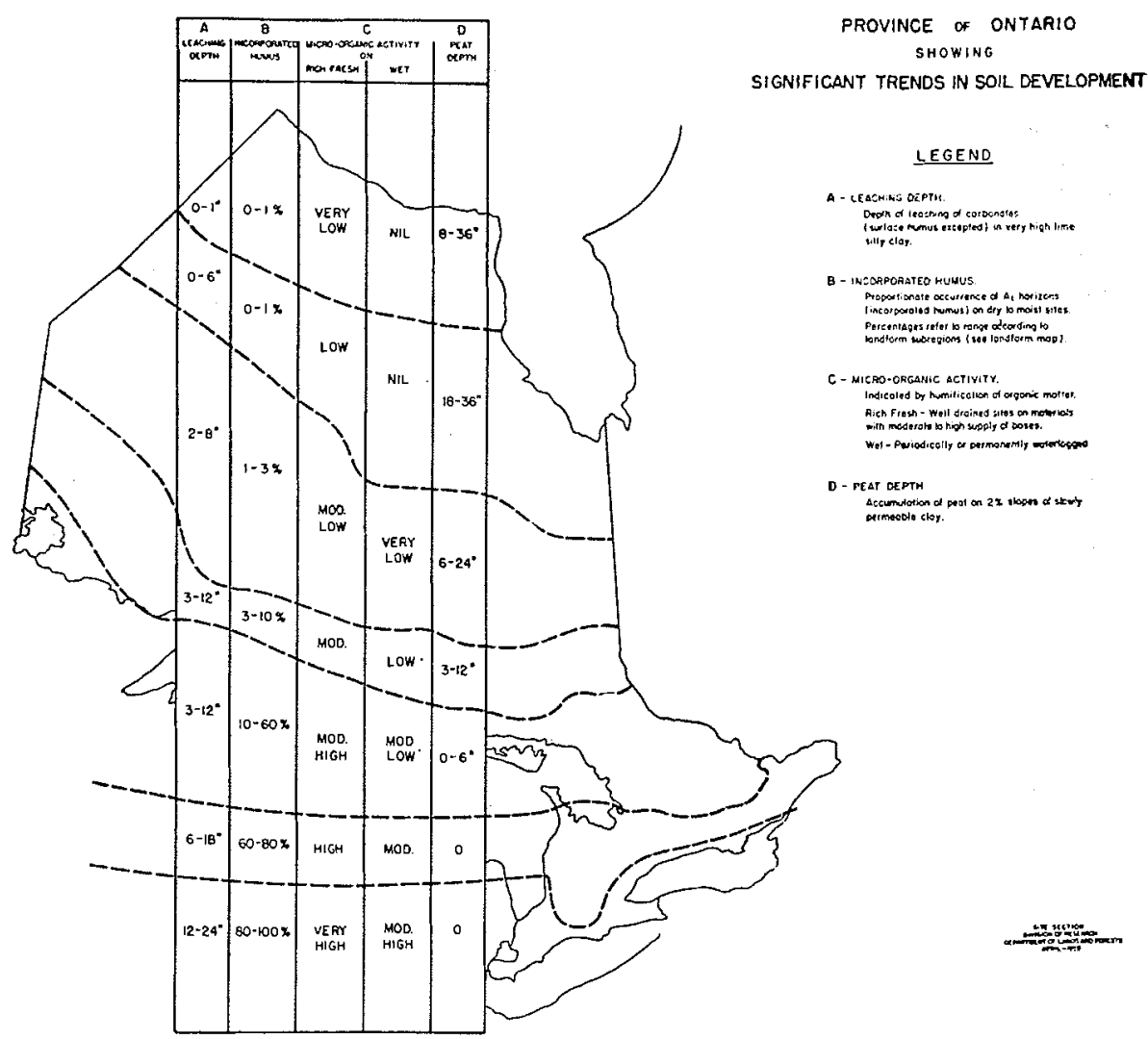

graphic conditions which provide for the development of the best agricultural soils, are also those which provide the best environment for forest, even though the soil-forming processes under forest management differ in degree, if not in kind, from those which proceed under farm management.

In the subhumid regions, fresh soils with the best breakdown of humus and with the best incorporation of organic and mineral matter are not always the best forest soils.

The effect of climatic differences (particularly that of temperature) upon these soil-forming processes is shown on Map 3, under the headings of trends $B, C$ and $D$.

It will be noted that two physiographic sites are taken as references for the activity of micro-organisms. For the rich, fresh sites (i.e. well-drained, with a moderate to high supply of bases), region $7 \mathrm{E}$ in Southern Ontario is taken as having the highest degree of activity. It will be noted further, that the highest degree of activity on the wetter site conditions does not lie 
within the confines of Ontario. For this reference point, regions farther south must be sought.

A striking difference in the pattern of soil profile on poor, coarse-textured material is noted when regions along the Quebec boundary are compared to those adjacent to the Manitoba boundary. This difference suggests a significant control of effective air humidity on soil profile development.

Although most of the profiles developed in this material are podsols (Stobbe, 1960), these vary significantly depending upon the degree to which a cementation by iron and humus has developed. In going from the humid east to the subhumid west there is a marked decrease in the number of landform positions on which this cementation (ortstein formation) takes place. There is likewise a decrease in the intensity of this formation on similar landform positions.

It is now apparent that regional site research will include the establishment of the ranges in development of the various soil horizons within a site region.

\section{REgIoNs of Forests AND OF Forest Sites}

Regions are tools of convenience which geographers have developed for describing the areal distribution of natural phenomena (U.S. Nat. Res. Com., 1935, pp. 138-144). In keeping with the original scope of geography (ge-earth, graphe-description), the original meaning of the term region was an area chosen as a convenient unit for areal description (Hartshorne, 1935). The nature of the region, as developed in the description, depended in large part upon the objective and the ability of the geographer. Regional geography became a highly developed art from the standpoints of selecting areas having unique features and functions and of the actual literary description.

However, in order that it deal more adequately with the earth as the home of man, geography became, in part, a science, namely human ecology (U.S. Nat. Res. Com., 1935 pp. 145-149). In this science, absolute levels of the various environmental features are evaluated in terms of their significance in human occupance either directly, or indirectly, in terms of the distribution and production of materials (including crops) and services to meet human needs and desires. Gradients of factors are established and subdivided into segments of classes which show significant relationships between forest and environment. Areal units are circumscribed and defined by one or more of these classes. Areas which represent fairly broad segments of gradients, which gradients are of continental or semi-continental extent, are also regions.

An example of this latter type of region is the climatic region of Thornthwaite (1948) based on gradients of effective temperature and humidity. Thermal Efficiency Regions and Moisture Regions (Sanderson, 1948, pp. 504, 514) are single-factor regions, in contrast to the multi-factor regions, such as the climatic regions of Chapman (1953), and of Putnam and Chapman (1938) which attempt to integrate all the pertinent climatic factors. The site regions outlined in this paper are still more complex in that they are the integration of classes from gradients of landform, vegetation, climate and soil (Hills, 1958).

The use of gradient analysis and synthesis in the establishment of these regions does not destroy their true uniqueness, but rather permits the nature 
of this uniqueness to be better understood through providing a means of comparing one region with another. Neither should literary art be neglected in the description of the gradient-defined units which characterize the regions.

These regions, established by the differentiation of continental gradients into broad classes and the integration of one or more classes from two or more gradients to form areal units, may be described as both geographic and ecologic. Neither of these terms is entirely satisfactory since both have been used with narrower meanings (Hills, 1958). Regions based on ecologic relationships within a continental continuum could be referred to as gradient-defined regions, and the original geographic regions could be called areally-described regions. Both types of regions are useful in the dissemination of knowledge. The fullest use of both types can only be made through an understanding of their differing roles. Accordingly, a brief comparison is presented below of the ways in which the forests of Ontario have been treated from these two points of view.

Halliday (1937), in the introduction to his monumental work on the forest regions of Canada, stated that his objective was to establish ecologic regions based on "the relationship of the plant community to the habitat". However, Rowe (1959 pp. 7-9), in a recent revision of Halliday's memoir, clearly stated that the purpose of the forest regions, in both the original and in the revision, is "areal forest description".

Thus, in its present form, the Forest Regions of Canada accomplishes the objective of presenting areally-described units based on forest characteristics only. These are geographic regions in the original meaning of the term. They are not geographic-ecologic units in the broader meaning developed above, for Rowe (1959) makes it very clear that they are not ecologic either in the sense of Clements (Halliday, 1937) or in the sense of forest production systems as used in this paper.

At this point the writer of this paper would like to add his word of appreciation to those of the many who have found Halliday's framework an incentive to ecologic discovery. For although the regions of Halliday and Rowe are not organized on an ecologic basis, the areal description of the forests and of the climate and soils, with which they are associated, has been so well presented that many forest-habitat relationships have become evident. This, however, does not justify the continued reference to these regions and sections as "ecologic regions" as defined herein.

As discussed above, the site regions proposed in this paper are regions defined in terms of ecologic gradients. They are initially circumscribed and defined by subdividing continental gradients of landform and of forests into classes based upon the relationships between these two features. Specific gradients are then established for each region in order to establish, in greater detail, the forest-environment relationships within the region to provide a sound basis for forest management. Intra-regional detail for a number of regions provides for a fuller description of inter-regional differences.

A high degree of coincidence is found when the boundaries of the site regions of Ontario are compared with the boundaries of the forest regions of Rowe (1959), or with groups of forest sections into which these regions are divided. This is logical in that the forest whose distribution is indicated 
by forest regions is also a component of the site complex whose distribution is shown by site regions. However, this coincidence does not necessarily follow, since the objectives of the two studies are different.

The most important difference between the two methods lies in the inter-regional and intra-regional organization of the site regions. Take, for example, the three site regions $6 \mathrm{E}, 5 \mathrm{E}$ and $4 \mathrm{E}$ which occupy an area coincident with that of Rowe's Great Lakes and St. Lawrence Forest Region. Examine closely his forest sections $L_{1}, L_{4} d$, and $L_{s}$ which are located within site regions $6 \mathrm{E}, 5 \mathrm{E}$ and $4 \mathrm{E}$ respectively.

From Rowe's areal description of these sections, it is clear that they lie in three belts, in which the more southerly occurring hardwoods are replaced in stages by boreal species. Except for a few casual remarks, Rowe does not attempt to indicate the landform positions occupied by the two main components of the Great Lakes - St. Lawrence Forest namely the tolerant hardwoods and the white-and-red pine forests in each of these regions. This, he claims, is not the purpose of the bulletin.

On the other hand, the forest site region organization provides for ecologic relationships at increasing degrees of detail as one studies site regions, site districts and local areas. The key to the map of site regions indicates the physiographic niches occupied by the various species under the least disturbed conditions. Hard maple and yellow birch occupy but one niche in region $4 \mathrm{E}$, and this is one which is of infrequent occurrence. Hard maple and yellow birch occupy two physiographic niches in region $5 \mathrm{E}$, but these are the most frequently occurring landform positions. In region $6 \mathrm{E}$, tolerant hardwoods of all types occupy six of the nine physiographic niches, but the maple-yellow birch forest, characteristic of region $5 \mathrm{E}$, occupies but two of these. The characteristic hardwood type of region $6 \mathrm{E}$ is the hard maple-beech forest which occurs on but one physiographic niche in region $5 \mathrm{E}$ and then only to a limited degree.

The distribution pattern and physiographic relationships of white and red pine, another major component of the Great Lakes - St. Lawrence Forest, can be similarly traced from the key. The implications of forest succession are of even greater importance to forest management than is the physiographic distribution of the major species, per se. For example, the proportion of physiographic sites on which white pine regeneration is inhibited by the development of hardwood competition becomes less as one goes from region $6 \mathrm{E}$ to region 4E. There is also a lessening of the degree to which hardwood competition interferes with white pine regeneration on the same physiographic niche as one goes from $6 \mathrm{E}$ to $4 \mathrm{E}$.

The ultimate detailed explanation of the significant forest-landform-soil relationships within the site regions lies within the scope of reports of the reference areas discussed below.

Reference Area-A Method of Site Research

Since site regions cover large areas, the findings of regional site research can be expressed concretely through the use of reference area studies (Hills and Boissonneau, 1960; Hills and Brown, 1955; Hills and Pierpoint, 1960; Pierpoint, 1960).

A site reference area is an area of comparatively small size, characterized 
by physiography and forest types which are representative of those occurring commonly throughout broad areas, and which are mapped and described with such thoroughness and detail that the photographs, maps and report will serve as a reference for forest managers and other land-use planners. Ecological units (Hills and Brown 1955) are established which are based on simple interrelationships between combinations of effective physiography and vegetation. These provide the complex of interacting features of forest production within which the effect of variations in levels of single factors, such as available soil potassium, may be measured.

The reference area should be looked upon as an experimental area in which nature, either alone or assisted by man, has tried out many tests. By means of maps and reports a record is made of (a) the steps in the "experiment," in so far as the research worker is able to construct them, and (b) his conclusions concerning the dynamic development of forests within specific combinations of physiography and vegetation types, and under various types and degrees of disturbances by both nature and man. It is recognized that the conclusions obtained in this way are subjective in nature because they are based on many observations of "interpreted" levels rather than on an objective mathematical treatment of "measured" levels. It should be recognized, however, that objective experiments (limited in number, as they are, by such controls as cost and rotation age of forests, etc.) can be more profitably carried out within this subjective framework.

Reference areas established by regional research are designed to assist other programs in forestry and in multiple land-use planning such as the following:

(a) Programs to familiarize foresters with the physiographic and biotic sites of the region and their significance in the development and growth of the forest and in the management of forest resources. (Hills, 1952)

(b) Air-photograph interpretation of the physiographic sites of the area which the reference area represents. (Burger, 1957; Hills, 1950).

(c) Mapping of cover types: (i) present, (ii) stable (climax) (Hills and Brown, 1955).

(d) Silvicultural experimentation (Burton, 1960).

(e) Grouping of physiographic sites in terms of forest productivity (rate and quality of growth and possibilities of regeneration) (Hills and Pierpoint, 1960).

(f) Assessment of problems and program planning in reforestation.

(g) Studies in forest pathology.

(h) Assessment of problems in forest management and the making of management plans.

(i) Grouping of ecological units of significance in wildlife management and in recreational use of land.

(j) Evaluation of potential for agricultural development (Hills and Boissonneau, 1960).

BURGER, D. 1957. Identification of Forest Soils on Aerial Photographs. For. Chron. 33(1): 54-60.

BURTON, D. H. 1960. Yellow Birch Regeneration Studies at Swan Lake. Ont. Dept. of Lands \& Forests, Research Rpt. (to be published). 
CHAPMAN, L J. 1953. The Climate of Northern Ontario. Can. Jour. Agr. Sci, 33: 41-73. HALliDAY, W. E. D. 1937. A Forest Classification for Canada. Can. Dept. of Mines \& Resources, Forest Service-Bull. 89.

HARTSHORNE, R. 1935. The Nature of Geography. Annals. Ass. of Am. Geog. 29(3, 4).

HIILS, G. A. 1950. The Use of Aerial Photographs in Mapping Soil Sites. For. Chron. 26(1): 4-37.

.1952. The Classification and Evaluation of Site for Forestry. Ont. Dept. of Lands \& Forests, Research Rpt. 24.

1953. The Use of Site in Forest Management. For. Chron. 29(2): 128-136.

. 1954. Field Methods for Investigating Site. Ont. Dept. of Lands \& Forests, Site Researcb Man. 4 (Revised 1957).

- 1958. Soil Forest Relationships in the Site Regions of Ontario. First North-American Forest Soils Conference, East Lansing, 1958. Bull. Ag. Exp. Sta., Michigan State University, pp. 190-212.

. 1959. A Ready Reference to the Description of the Land of Ontario and its Productivity. Preliminary Rpt., Ont. Dept. of Lands \& Forests, Maple, Ontario.

- 1960 (a). Comparison of Forest Ecosystems (Vegetation and Soil) in Different Climatic Zones. Forest Ecosystem Symp., IXth Intern. Bot. Congress, Montreal, 1959. Silva Fennica, 105.

1960 (b). The Soils of the Canadian Shield. Agricultural Institute Review. March, 1960. . 1960 (c). The Classification of Forest Productivity Systems (Site, Ecosystem, Biogeocoenose). Special paper presented at Fifth World Forestry Congress, Seattle, Washington, Aug./Sept. 1960.

and A. N. BOISSONNEAU. 1960. Land Use Research Supplements to "A Multiple Land-Use Plan for the Glackmeyer Development Area". Report, Ont. Dept. of Lands Forests and Ont. Dept. of Agriculture (in press).

and W. G. E. BROWN. 1955. The Sites of the University of Toronto Forest. Ont. Dept. of Lands \& Forests. (Mimeographed copies prepared for North-Eastern Forest Soils Conference, Dorset, Ont.)

and G. PIERPOINT. 1960. Forest Site Evaluation in Ontario. Ont. Dept. of Lands \& Forests, Research Rpt. No. 42.

KRAJINA, V. J. 1960(a). Can we Find a Common Platform for the Different Schools of Forest Type Classification? Contr. Forest Ecosystem Symp., IXth Intern. Bot. Congress, Montreal, 1959. Silva Fennica 105.

- $1960(b)$. Ecosystem Classification of Forests. (Being a summary of all contributions to the symposium prepared to provide time for discussion). Contr. Forest Ecosystem Symp. IXth Intern. Bot. Congress, Montreal, 1959. Silva Fennica 105.

OVINGTON, J. D. 1960. The Ecosystem as an Aid to Forest Classification. Contr. Forest Ecosystem Symp., IXth Intern. Bot. Congress, Montreal, 1959. Silva Fennica 105.

PIERPOINT, G, 1960. The Sites of the Kirkwood Management Unit. Ont. Dept. of Lands \& Forests. Research Rpt. (to be published).

PUTNAM, D. F., and L. J. Chapman. 1938. The Climate of Southern Ontario. Sci. Agr. 18: $401-446$.

ROWE, J. S. 1959. Forest Regions of Canada. Canada Dept. of Northern Affairs \& National Resources, Forestry Branch, Bull. 123.

- HADDOCK, P. G., HILLS, G. A., KRAJINA, V. J., and A. LINTEAU. 1960. The Ecosystem Concept in Forestry. Summary of proposals to the Fifth World Forestry Congress by members of the Forest Ecosystem Symposium, IXth Intern. Bot. Congress, Montreal, 1959.

SANDERSON, M. 1948. The Climates of Canada according to the New Thornthwaite Classification. Sci. Agr. 28: 501-517.

Society of American Foresters. 1950. Forestry Terminology, p. 75.

STOBBE, P. C. 1960. The Origin, Nature and Distribution of the Soils of Canada. Agricultural Institute Review, March, 1960.

THORNTHWAITE, C. W. 1948. An Approach toward a Rational Classification of Climate. Geographical Review 38(1): 55-94.

United States Natural Resources Committee. 1935. Regional Factors in National Planning and Development. Rpt. U.S. Gov. Printing Office, Washington, D.C.

WHITTAKER, R. H. 1957. The Kingdoms of the Living World. Ecology 38(3). 